\title{
Safety of denervation following targeted lung denervation therapy for COPD: AIRFLOW-1 3-year outcomes
}

\author{
Christophe Pison ${ }^{1,2^{*}} \mathbb{0}$, Pallav L. Shah ${ }^{3}$, Dirk-Jan Slebos ${ }^{4}$, Vincent Ninane ${ }^{5}$, Wim Janssens ${ }^{6}$, Thierry Perez ${ }^{7}$, \\ Romain Kessler ${ }^{8}$, Gaetan Deslee ${ }^{9}$, Justin L. Garner ${ }^{3}$, Jorine E. Hartman ${ }^{4}$, Bruno Degano ${ }^{1,2}$, Anna Mayr ${ }^{10}$, \\ Martin Mayse ${ }^{11}$, Alexander D. Peterson ${ }^{11}$ and Arschang Valipour ${ }^{10}$
}

\begin{abstract}
Background: Targeted lung denervation (TLD) is a novel bronchoscopic therapy that disrupts parasympathetic pulmonary nerve input to the lung reducing clinical consequences of cholinergic hyperactivity. The AIRFLOW-1 study assessed safety and TLD dose in patients with moderate-to-severe, symptomatic COPD. This analysis evaluated the long-term impact of TLD on COPD exacerbations, pulmonary function, and quality of life over 3 years of follow up.

Methods: TLD was performed in a prospective, energy-level randomized (29 W vs $32 \mathrm{~W}$ power), multicenter study (NCT02058459). Additional patients were enrolled in an open label confirmation phase to confirm improved gastrointestinal safety after procedural modifications. Durability of TLD was evaluated at 1,2, and 3 years post-treatment and assessed through analysis of COPD exacerbations, pulmonary lung function, and quality of life.

Results: Three-year follow-up data were available for $73.9 \%$ of patients $(n=34)$. The annualized rate of moderate to severe COPD exacerbations remained stable over the duration of the study. Lung function ( $F E V$, FVC, RV, and TLC) and quality of life (SGRQ-C and CAT) remained stable over 3 years of follow-up. No new gastrointestinal adverse events and no unexpected serious adverse events were observed.
\end{abstract}

Conclusion: TLD in COPD patients demonstrated a positive safety profile out to 3 years, with no late-onset serious adverse events related to denervation therapy. Clinical stability in lung function, quality of life, and exacerbations were observed in TLD treated patients over 3 years of follow up.

Keywords: COPD, Nerves, Targeted lung denervation, Acetylcholine, Anticholinergic, Bronchoscopy

\section{Background}

COPD is characterized by persistent limitation of airflow and respiratory symptoms resulting from abnormalities in the lungs at the level of the alveoli, airways, or both $[1,2]$. COPD exacerbations are associated with high

\footnotetext{
*Correspondence: cpison@chu-grenoble.fr

1 Service Hospitalier Universitaire Pneumologie Physiologie, Pôle Thorax et Vaisseaux, CHU Grenoble Alpes, CS10217, 38043 Grenoble Cedex 9, France

Full list of author information is available at the end of the article
}

costs, poor clinical prognosis, increased morbidity and increased mortality; therefore, reducing the risk of exacerbations in the COPD population is an important treatment goal $[1,3,4]$.

The pathophysiology of COPD is characterized by increased autonomic nervous system input to the lung and sensory signaling from the lung mediated by the vagus nerve. Increased parasympathetic input raises cholinergic tone in the airways which modulates airway smooth muscle tone, airway hyperresponsiveness, inflammation and mucus hypersecretion [5-7]. Thus, one of the cornerstones of COPD pharmaceutical 
management is to reduce symptoms by blocking cholinergic signaling with anticholinergic agents. Anticholinergic agents relax airway smooth muscle, decrease mucus hypersecretion, and improve COPD-related symptoms $[1,8]$.

Medical therapy has limitations and leaves significant unmet needs for COPD patients [1,9-11]. Patient compliance to prescribed inhaled medications and optimal deposition of medication into the lung periphery remain challenges [12]. Acute changes in lung physiology due to infections/inflammation overwhelm the therapeutic effect of inhaled medications [13]. As a result, patients continue to exacerbate while on medical therapy, with only about $50 \%$ of patients treated with a long acting muscarinic antagonist experiencing a clinically significant benefit [14] and up to $70 \%$ of patients experiencing a COPD exacerbation while on optimal medical therapy [11].

Targeted lung denervation (TLD) is a novel bronchoscopic therapy that interrupts parasympathetic pulmonary nerve input to the lung to reduce clinical consequences of cholinergic hyperactivity [15-17]. Previous research of TLD has established an optimal dosing strategy and the safety of the procedure $[16,18]$. This study presents the long-term impact of TLD on COPD exacerbations, symptoms, quality of life and pulmonary function at 3 years post-TLD as observed in the AIRFLOW-1 clinical trial.

\section{Methods}

Briefly, TLD therapy is delivered via a dual-cooled radiofrequency (RF) catheter (Nuvaira, Minneapolis, Minnesota, USA) designed to target tissue heating at depth, thereby producing a narrow band of ablation around the main bronchi while minimizing effects to the inner surface of the airway. As RF current passes from the electrode through the airway and surrounding tissues, these tissues are heated. Coolant continuously circulated through the electrode and balloon removes heat from the surface of the airway wall. The net effect is targeted tissue ablation at depth with minimal heating and damage of the inner surface of the airway [15-17].

AIRFLOW-1 was a randomized (1:1) double-blind multicenter study (NCT02058459) of 30 patients with moderate-to-severe symptomatic COPD that underwent TLD at $29 \mathrm{~W}(\mathrm{n}=15)$ or $32 \mathrm{~W}(\mathrm{n}=15)$ power. An additional 16 patients were treated with $32 \mathrm{~W}$ power, associated with optimal improvements in $\mathrm{FEV}_{1}$ and SGRQ-C, after randomization as an open-label group to confirm safety improvements after procedural enhancements following gastrointestinal adverse events during the randomized part of the trial [16]. Detailed descriptions of the study methodology have been previously published [16].
All patients signed a written informed consent form, and study approval was obtained from local ethics committees and in accordance with the Declaration of Helsinki (1996), Good Clinical Practice guidelines, and any local requirements.

Gastrointestinal events were reported during the randomization phase, which led to procedural modifications and a subsequent reduction in treatment-related gastric side-effects in the open-label phase [16]. The procedural change was the addition of esophageal balloon placement allowing the physician to visualize the esophagus and fluoroscopically measure the distance between the radiofrequency (RF) electrode and the esophagus. Additionally, a treatment plan was developed to lower the energy dose depending on proximity to the esophagus.

\section{Outcome measures}

TLD's impact on COPD exacerbations (moderate to severe) along with pulmonary lung function and healthrelated quality of life was evaluated at 1,2 , and 3 years post-treatment. Patient flow through the study from baseline through the 3-year follow-up is described in Fig. 1. Washout measures of pulmonary lung function evaluated were $\mathrm{FEV}_{1}, \mathrm{FVC}, \mathrm{RV}$, and TLC and were compared with baseline at 1,2 , and 3 years post-treatment. Health-related quality of life was measured with the COPD-specific St. George's Respiratory questionnaire (SGRQ-C) and COPD Assessment Test (CAT) and compared with baseline at 1,2 , and 3 years post-TLD.

\section{Statistical analysis}

Statistical hypothesis tests were performed on all subjects $(n=46)$ combined into one group as sample size of individual groups was small. Tests were based on paired t-tests for repeated and continuous data that are normally distributed. Non-parametric tests were performed when there was evidence of non-normality. Data at 1,2, and 3-year time points were compared against baseline and $\mathrm{P}<0.05$ was considered statistically significant.

\section{Results}

A total of 46 patients were treated with TLD during the initial study enrollment period; baseline characteristics have been previously described [16]. Retention was high with $80.4 \%$ follow-up at 2 years and $73.9 \%$ follow-up at 3 years (Fig. 1).

\section{Safety}

Over the 2nd and 3rd years of follow-up, there were no new gastrointestinal serious adverse events related to the procedure or device (SAEs; Table 1). A patient in the confirmation group experienced a gastric SAE at 650 days post procedure. While the primary gastrointestinal 


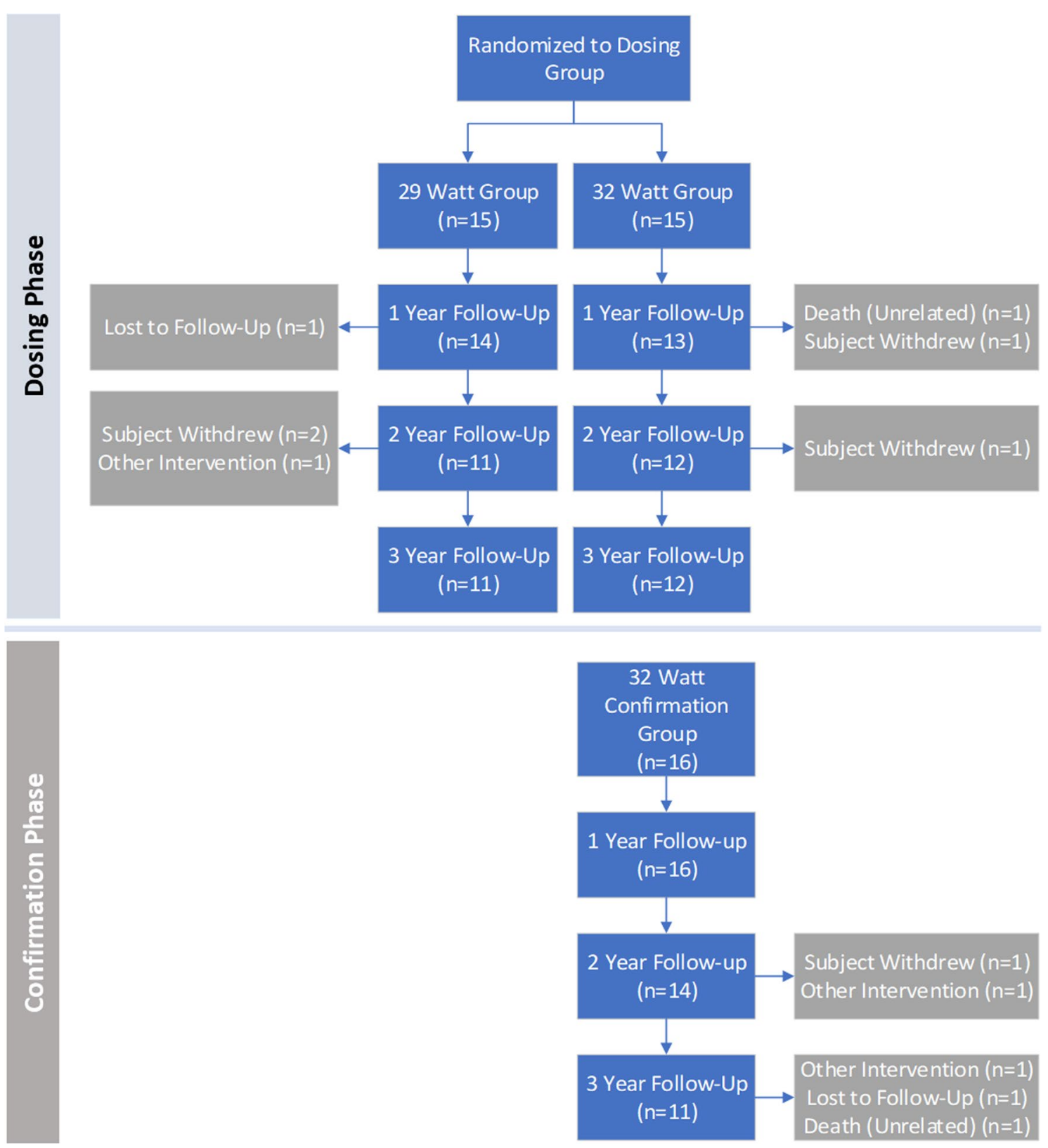

Fig. 1 Participant flow through the study. Dosing phase for the $29 \mathrm{~W}$ and $32 \mathrm{~W}$ groups and confirmation phase for the unblinded $32 \mathrm{~W}$ confirmation group

Table 1 Serious adverse events

\begin{tabular}{|c|c|c|c|c|c|c|c|c|c|c|c|c|}
\hline \multirow[t]{2}{*}{ Group (\# subjects) } & \multicolumn{3}{|c|}{ All-cause } & \multicolumn{3}{|c|}{ Respiratory } & \multicolumn{3}{|c|}{ Gastrointestinal } & \multicolumn{3}{|c|}{ Cardiac } \\
\hline & Year 1 & Year 2 & Year 3 & Year 1 & Year 2 & Year 3 & Year 1 & Year 2 & Year 3 & Year 1 & Year 2 & Year 3 \\
\hline $29 W(n=15)$ & $9(16)$ & $1(1)$ & $5(9)$ & $3(5)$ & $1(1)$ & $5(8)$ & $6(7)$ & $0(0)$ & $0(0)$ & $0(0)$ & $0(0)$ & $0(0)$ \\
\hline $32 W(n=15)$ & $5(14)$ & $1(1)$ & $5(9)$ & $3(5)$ & $0(0)$ & $4(6)$ & $3(4)$ & $0(0)$ & $0(0)$ & $2(2)$ & $1(1)$ & $1(1)$ \\
\hline 32 W-CFM $(n=16)$ & $5(9)$ & $6(9)$ & $6(8)$ & $4(4)$ & $6(6)$ & $5(6)$ & $0(0)$ & $1(1)$ & $0(0)$ & $0(0)$ & $1(1)$ & $2(2)$ \\
\hline
\end{tabular}


events experienced during the randomization phase were impaired gastric emptying, this patient experienced

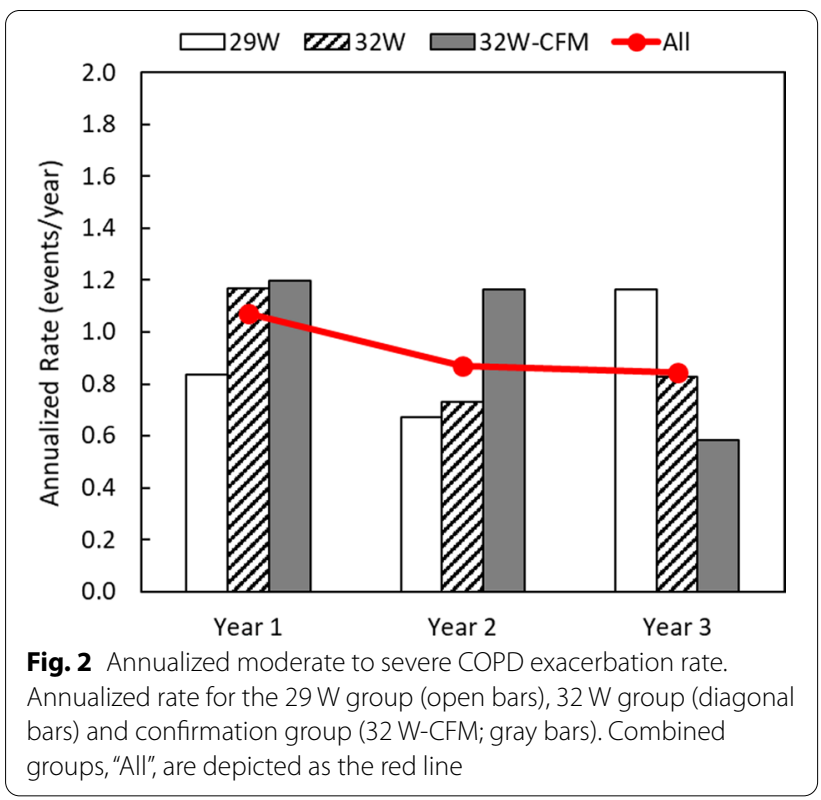

increased dysphagia which fully resolved and was determined not to be related to the procedure or the device. There was one death in the confirmation group 1128 days post procedure (Fig. 1). The acute cardiac death was determined unrelated to TLD and no autopsy was performed. No unanticipated SAEs were seen 3 years out from the TLD procedure in lung denervated patients (Table 1).

The percentage of patients having at least one moderate or severe COPD exacerbation was $70 \%$ (31/44), $61 \%$ $(23 / 38)$, and $46 \%(16 / 35)$ at the 1,2 and 3-year followup respectively. Annualized rate of moderate or severe COPD exacerbations remained stable over the duration of the study (Fig. 2).

\section{Pulmonary function and quality of life}

Both $\mathrm{FEV}_{1}$ and $\mathrm{FVC}$ improved at 1 year relative to baseline with average increases of $60 \mathrm{~mL}(\mathrm{P}=0.031)$ and $219 \mathrm{~mL}(\mathrm{P}=0.004)$ respectively. These measures were not significantly different from baseline at the 2 and 3-year follow-up visits. Figure 3 shows that overall lung function $\left(\mathrm{FEV}_{1}, \mathrm{FVC}, \mathrm{RV}\right.$, and TLC) was stable during the


Fig. 3 Long-term lung function. a FEV 1 , b, FVC, c RV, and $\mathbf{d}$ TLC for the $29 \mathrm{~W}$ group (open bar), $32 \mathrm{~W}$ group (diagonal line bar) and $32 \mathrm{~W}$ confirmation group (32 W-CFM, gray bar) collected at baseline, 1, 2, and 3 years after TLD. Data presented are means \pm SD. Combined values, "All", are depicted as the red line. $P<0.05$ for combined values compared with baseline is denoted by *. FEV forced expiratory volume in $1 \mathrm{~s}$, FVC forced vital capacity, $R V$ residual volume, $T L C$ total lung capacity, TLD targeted lung denervation 
3 years of follow-up. CAT also improved at 1 year relative to baseline with an average decrease of -3.03 points $(\mathrm{P}=0.032)$ but was not significantly different at the 2 or 3 -year follow-up visits. Figure 4 shows that overall quality of life and symptoms (SGRQ and CAT) were stable during the 3 years of follow up.

\section{Discussion}

These data add to previously published research on the safety and feasibility of the TLD procedure [15-18]. Three years of follow-up demonstrate a positive longterm safety profile, and no new GI-related SAEs related to the procedure or device over the 2nd and 3rd year of follow up. Patients treated with TLD had stable lung function and symptom levels at 3 years post treatment.

A previously published TLD clinical study using an earlier version of the device not yet compatible with flexible bronchoscopy also followed subjects for 3 years of follow-up [17]. Both long-term studies utilizing different generation devices and associated doses yielded results supporting favorable long-term safety. In addition, the absence of unexpected severe adverse events
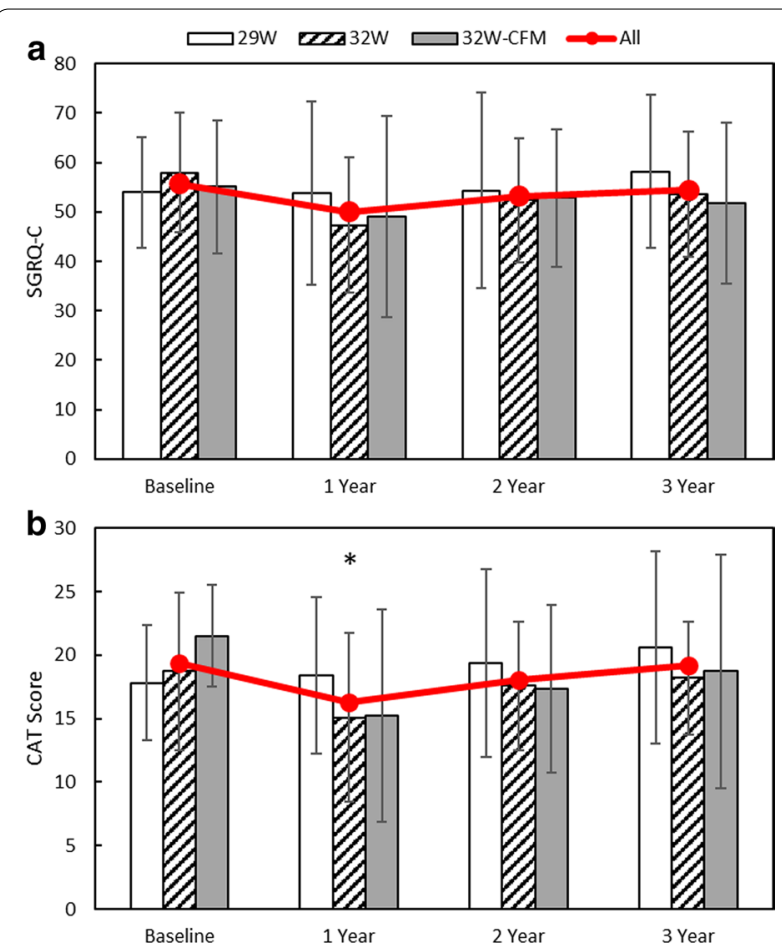

Fig. 4 Quality of life assessment. a Saint George's Respiratory Questionnaire (SGRQ-C) and $\mathbf{b}$ COPD assessment test (CAT) for the 29 W group (Open Bars), 32 W Group (hashed bars), and 32 W confirmation group (32 W-CFM; solid gray bars) at baseline, 1, 2, and 3 years. Values are mean \pm SD. Combined values, "All", are depicted as the red line. $P<0.05$ for combined values compared with baseline is denoted by * in the confirmation group indicates that the procedural modifications to fluoroscopically measure distance from the esophagus did not result in any unanticipated adverse events during later years [16].

It is well established that lung function in COPD patients continues to decline with progression of the disease. Prior longitudinal studies across a wide range of GOLD stage COPD patients has consistently reported an average annual rate of decline in $\mathrm{FEV}_{1}$ and $\mathrm{FVC}$ to be $\sim 30 \mathrm{~mL} /$ year and $\sim 40 \mathrm{~mL} /$ year respectively $[19,20]$. Annual decline in $\mathrm{FEV}_{1}$ specific to GOLD Stage II and III COPD patients has been reported to range from $\sim 40-80 \mathrm{~mL} /$ year and $\sim 30-60 \mathrm{~mL} /$ year respectively [21, 22]. Similarly, decline in patient reported quality of life measures have been reported in COPD patients with an average yearly increase in SGRQ-C of 1.2 to 1.8 points being reported $[19,23]$.

Previous TLD clinical studies have demonstrated potential positive impacts on lung function and quality of life measures in patients with COPD [15-18]. The current results suggest that these impacts on lung function and COPD symptoms remained largely stable over the 3 years of follow up. At 3 years post-treatment, measures of lung function $\left(\mathrm{FEV}_{1}, \mathrm{FVC}, \mathrm{RV}\right.$, and TLC) and quality of life (SQRG-C and CAT) on average were similar to baseline measures and absent of significant declines.

Follow-up bronchoscopy was performed at 3 months post-treatment checking for presence of adverse reactions within the airways such as narrowing, stenosis, fibrosis, etc. Although no follow-up bronchoscopy was performed at later time points, stability of lung function may also support the absence of long-term adverse airway reactions occurring beyond 3 months post-treatment.

The current study has limitations, principally the small cohort size, and a lack of a sham-control group. However, a strength of this study is its high retention through 3 years of follow-up, which is rare in early-stage device trials. Moreover, any placebo effect assumed by the openlabel design would not be expected to impact 2 or 3-year measures. The absence of decline three years post-treatment compared with baseline supports stability for lung function and quality of life in this study and both are consistent with the stable rate of exacerbations observed in this study [24]. These observations will need to be confirmed in an ongoing large scale sham-controlled randomized trial (AIRFLOW-3) comparing the efficacy of TLD plus optimal medical care for patients with moderate-to-severe COPD against optimal medical care for COPD [25]. 


\section{Conclusion}

In summary, the current study provided long-term followup data on TLD and confirmed a positive safety profile out to 3 years. Moderate-to-severe COPD patients treated with TLD demonstrated clinical stability in lung function, symptoms, quality of life, and exacerbations over 3 years of follow-up. No late onset gastrointestinal events or adverse events related to targeted lung denervation therapy were reported.

\begin{abstract}
Abbreviations
CAT: COPD assessment test; COPD: Chronic obstructive pulmonary disease; CFM: ConFirMation; FEV : Forced expiratory volume $1 \mathrm{~s}$; FVC: Forced volume capacity; GOLD: Global initiative on Obstructive Lung Disease; RV: Residual volume; SGRQ-C: Saint Georges Respiratory Questionnaire-C; TLC: Total lung capacity; TLD: Targeted lung denervation; RF: Radio frequency; SAE: Serious adverse event; W: Watt.
\end{abstract}

\section{Acknowledgements}

The authors thank the entire AIRFLOW-1 research team for their dedication to this trial. Additionally, the authors thank NAMSA for statistical analysis support.

\section{Authors' contributions}

All authors made a substantial contribution to the work whether that was through patient follow-up, interpretation of the data, or drafting of the manuscript. All authors participated in review and revision of the manuscript before approving it for submission and agreeing to be accountable for the work. All authors read and approved the final manuscript.

\section{Funding}

The AIRFLOW-1 clinical trial was funded by Nuvaira, Inc., Minneapolis, MN, USA.

\section{Availability of data and materials}

Data are available on demand at Nuvaira, Inc., Minneapolis, MN, USA.

\section{Ethics approval and consent to participate}

Subjects who participated in the AIRFLOW 1 clinical trial have given their informed consent to participate in this trial. The study protocol was approved by each research institutions committee on human research, see Ref. [16].

\section{Consent for publication}

The authors do not plan to share individual deidentified participant data.

\section{Competing interests}

The AIRFLOW-1 clinical trial was funded by Nuvaira, Inc., Minneapolis, MN, USA. PLS and DJS are investigators and advisors to Nuvaira, Inc. ADP and MM are employees of Nuvaira, Inc. CP, VN, WJ, TP, RK, GD, JLG, JEH, BD, AM, AV have nothing to disclose in relation to this work.

\footnotetext{
Author details

${ }^{1}$ Service Hospitalier Universitaire Pneumologie Physiologie, Pôle Thorax et Vaisseaux, CHU Grenoble Alpes, CS10217, 38043 Grenoble Cedex 9, France. ${ }^{2}$ Université Grenoble Alpes, Grenoble, France. ${ }^{3}$ Royal Brompton \& Harefield NHS Trust, Chelsea \& Westminster Hospital and Imperial College, London, UK. ${ }^{4}$ Department of Pulmonary Diseases, University of Groningen, University Medical Center Groningen, Groningen, The Netherlands. ${ }^{5} \mathrm{CHU}$ Saint-Pierre, Université Libre de Bruxelles, Brussels, Belgium. ${ }^{6}$ Department of Respiratory Diseases, KU Leuven, University Hospitals Leuven, Leuven, Belgium. ${ }^{7} \mathrm{CHU}$ Lille, Center for Infection and Immunity of Lille, INSERM U1019-UMR9017, Univ Lille Nord de France, Lille, France. ${ }^{8}$ Service de Pneumologie, Nouvel Hôpital Civil, Université de Strasbourg, Strasbourg, France. ${ }^{9}$ Service de Pneumologie, INSERM UMRS-1250, CHU de Reims, Hôpital Maison Blanche, Reims, France. ${ }^{10}$ Department of Respiratory and Critical Care Medicine, Karl-LandsteinerInstitute for Lung Research and Pulmonary Oncology, Klinik Floridsdorf, Vienna, Austria. ${ }^{11}$ Nuvaira, Inc., Minneapolis, MN, USA.
}

Received: 12 December 2020 Accepted: 11 February 2021

Published online: 19 February 2021

\section{References}

1. Global Initiative for Chronic Obstructive Lung Disease (GOLD). Global Strategy for the Diagnosis, Management, and Prevention of Chronic Obstructive Pulmonary Disease (2020 Report). 2020 December 3, 2019. https://goldcopd.org/wp-content/uploads/2019/12/GOLD-2020-FINAL -ver1.2-03Dec19 WMV.pdf. Accessed 12 Feb 2020.

2. Singh D, Agusti A, Anzueto A, Barnes PJ, Bourbeau J, Celli BR, Criner GJ, Frith P, Halpin DMG, Han M, López Varela MV, Martinez F, Montes de Oca M, Papi A, Pavord ID, Roche N, Sin DD, Stockley R, Vestbo J, Wedzicha $J A$, Vogelmeier C. Global strategy for the diagnosis, management, and prevention of chronic obstructive lung disease: the GOLD science committee report 2019. Eur Respir J. 2019;53(5):1900164.

3. Lopez-Campos JL, Tan W, Soriano JB. Global burden of COPD. Respirology 2016;21(1):14-23.

4. Rothnie KJ, Müllerová H, Smeeth L, Quint JK. Natural history of chronic obstructive pulmonary disease exacerbations in a general practice-based population with chronic obstructive pulmonary disease. Am J Respir Crit Care Med. 2018;198(4):464-71.

5. Canning BJ. Reflex regulation of airway smooth muscle tone. J Appl Physiol. 2006;101(3):971-85.

6. Gross NJ, Skorodin MS. Role of the parasympathetic system in airway obstruction due to emphysema. N Engl J Med. 1984;311(7):421-5.

7. Kistemaker LE, Gosens R. Acetylcholine beyond bronchoconstriction: roles in inflammation and remodeling. Trends Pharmacol Sci. 2015;36(3):164-71.

8. Kume H, Fukunaga K, Oguma T. Research and development of bronchodilators for asthma and COPD with a focus on G protein/KCa channel linkage and beta2-adrenergic intrinsic efficacy. Pharmacol Ther. 2015;156:75-89.

9. Clari M, Ivziku D, Casciaro R, Matarese M. The unmet needs of people with chronic obstructive pulmonary disease: a systematic review of qualitative findings. COPD. 2018;15(1):79-88.

10. Breekveldt-Postma NS, Koerselman J, Erkens JA, Lammers JW, Herings RM Enhanced persistence with tiotropium compared with other respiratory drugs in COPD. Respir Med. 2007;101 (7):1398-405.

11. Pavord ID, Chanez P, Criner GJ, Kerstjens HAM, Korn S, Lugogo N, Martinot JB, Sagara H, Albers FC, Bradford ES, Harris SS, Mayer B, Rubin DB, Yancey SW, Sciurba FC. Mepolizumab for eosinophilic chronic obstructive pulmonary disease. N Engl J Med. 2017;377(17):1613-29.

12. Lavorini F, Magnan A, Dubus JC, Voshaar T, Corbetta L, Broeders M, Dekhuijzen R, Sanchis J, Viejo JL, Barnes P, Corrigan C, Levy M, Crompton GK. Effect of incorrect use of dry powder inhalers on management of patients with asthma and COPD. Respir Med. 2008;102(4):593-604.

13. Zaccone EJ, Undem BJ. Airway vagal neuroplasticity associated with respiratory viral infections. Lung. 2016;194(1):25-9.

14. Casaburi R, Mahler DA, Jones PW, Wanner A, San PG, ZuWallack RL, Menjoge SS, Serby CW, Witek T Jr. A long-term evaluation of once-daily inhaled tiotropium in chronic obstructive pulmonary disease. Eur Respir 」. 2002;19(2):217-24.

15. Slebos DJ, Klooster K, Koegelenberg CF, Theron J, Styen D, Valipour A, Mayse M, Bolliger CT. Targeted lung denervation for moderate to severe COPD: a pilot study. Thorax. 2015;70(5):411-9.

16. Valipour A, Shah PL, Pison C, Ninane V, Janssens W, Perez T, Kessler R, Deslee G, Garner J, Abele C, Hartman JE, Slebos DJ, On behalf of the A-SG. Safety and dose study of targeted lung denervation in moderate/severe COPD patients. Respir Int Rev Thorac Dis. 2019;98(4):329-39.

17. Valipour A, Asadi S, Pison C, Jondot M, Kessler R, Benneddif K, Deslee G, Verdier M, Slebos DJ, Mayse M. Long-term safety of bilateral targeted lung denervation in patients with COPD. Int J Chronic Obstruct Pulm Dis. 2018;13:2163-72.

18. Slebos DJ, Shah PL, Herth FJ, Pison C, Schumann C, Hubner RH, Bonta PI, Kessler R, Gesierich W, Darwiche K, Lamprecht B, Perez T, Skowasch D, Deslee G, Marceau A, Sciurba FC, Gosens R, Hartman JE, Srikanthan K, Duller M, Valipour A, Group A-TS. Safety and adverse events after targeted lung denervation for symptomatic moderate to severe COPD (AIRFLOW): 
a multicenter randomized controlled trial. Am J Respir Crit Care Med. 2019;200(12):1477-86.

19. Tashkin DP, Celli B, Senn S, Burkhart D, Kesten S, Menjoge S, Decramer $M$, Investigators US. A 4-year trial of tiotropium in chronic obstructive pulmonary disease. N Engl J Med. 2008;359(15):1543-54.

20. Vestbo J, Edwards LD, Scanlon PD, Yates JC, Agusti A, Bakke P, Calverley PM, Celli B, Coxson HO, Crim C, Lomas DA, MacNee W, Miller BE, Silverman EK, Tal-Singer R, Wouters E, Rennard SI, Investigators E. Changes in forced expiratory volume in 1 second over time in COPD. N Engl I Med. 2011;365(13):1184-92

21. Sanchez-Salcedo P, Divo M, Casanova C, Pinto-Plata V, de-Torres JP, Cote C, Cabrera C, Zagaceta J, Rodriguez-Roisin R, Zulueta JJ, Marin JM, Celli B. Disease progression in young patients with COPD: rethinking the Fletcher and Peto model. Eur Respir J. 2014;44(2):324-31.

22. Tantucci C, Modina D. Lung function decline in COPD. Int J Chronic Obstruct Pulm Dis. 2012;7:95-9.
23. Oga T, Nishimura K, Tsukino M, Sato S, Hajiro T, Mishima M. Longitudinal deteriorations in patient reported outcomes in patients with COPD. Respir Med. 2007;101(1):146-53.

24. Halpin DM, Decramer M, Celli B, Kesten S, Liu D, Tashkin DP. Exacerbation frequency and course of COPD. Int J Chronic Obstruct Pulm Dis. 2012;7:653-61.

25. Slebos DJ, Degano B, Valipour A, Shah PL, Deslée G, Sciurba FC. Design for a multicenter, randomized, sham-controlled study to evaluate safety and efficacy after treatment with the Nuvair ${ }^{\circledR}$ lung denervation system in subjects with chronic obstructive pulmonary disease (AIRFLOW-3). BMC Pulm Med. 2020;20(1):41.

\section{Publisher's Note}

Springer Nature remains neutral with regard to jurisdictional claims in published maps and institutional affiliations.
Ready to submit your research? Choose BMC and benefit from:

- fast, convenient online submission

- thorough peer review by experienced researchers in your field

- rapid publication on acceptance

- support for research data, including large and complex data types

- gold Open Access which fosters wider collaboration and increased citations

- maximum visibility for your research: over $100 \mathrm{M}$ website views per year

At BMC, research is always in progress.

Learn more biomedcentral.com/submissions 